\title{
Jahrestagung 1986
}

Die Jahrestagung fand vom 15. bis 18. Oktober - nach 1927 und 1950 zum dritten Mal - in München statt.

In der Mitgliederversammlung wurde der seit der Freiburger Tagung 1985 verstorbenen Mitglieder der Vereinigung gedacht: Walther Meder, Helmut Rumpf und Herbert Wehrhahn. Die Vereinigung wird ihnen ein ehrendes Andenken bewahren. - Seit der letzten Jahrestagung sind sieben Kolleginnen und Kollegen neu in die Vereinigung aufgenommen worden, einer trat aus. Die Vereinigung zählt nunmehr 338 Mitglieder.

Die nächste Jahrestagung wird vom 7. bis 10 . Oktober 1987 in Passau, die folgende vom 5. bis 8 . Oktober in Tübingen stattfinden. Der Vorstand - Hans Zacher, Martin Kriele, Christian Tomuschat - wurde in geheimer Wahl wiedergewählt.

An der Tagung nahmen 222 Mitglieder teil, zum großen Teil mit ihren Ehefrauen. Darüber hinaus konnte der Vorsitzende einige ausländische Gäste aus Korea, Japan und Taiwan begrüßen. Ein besonderer Gruß galt dem Alterspräsidenten der Vereinigung, Hermann Jahrreiß, sowie den Kollegen, die schon an der Münchener Tagung vor 36 Jahren teilgenommen hatten und nun wieder dabei waren: Otto Bachof, Hans Peter Ipsen, Theodor Maunz, Hans Schneider und Hans Spanner. Die Vereinigung sandte Wilhelm Grewe ein Glückwunschtelegramm zu seinem 75. Geburtstag.

Vorträge und Diskussionen fanden im Hauptgebäude der Universität statt. Den Vorsitz führte Hans Zacher, die Diskussionen leiteten die Vorstandsmitglieder Martin Kriele und Christian Tomuschat.

Die Mitglieder der Vereinigung und ihre Damen waren am ersten Abend Gast des Universitätspräsidenten, Prof. Steinmann, am zweiten Abend Gast des Bayerischen Kultusministers Hans Maier in Vertretung des Bayerischen Ministerpräsidenten. Am dritten Abend fanden sie sich im Cuvillé-Theater zu einer Aufführung des „Brandner Kasper“ und anschließender Geselligkeit im Foyer zusammen. Der traditionelle Sonnabendausflug führte nach Dießen am Ammersee.

Dem in den Vorstand kooptierten Hans Ullrich Gallwas kam an der Vorbereitung der Tagung und - gemeinsam mit den Ehefrauen der Münchner Kollegen - des Rahmenprogramms großes Verdienst zu. 
